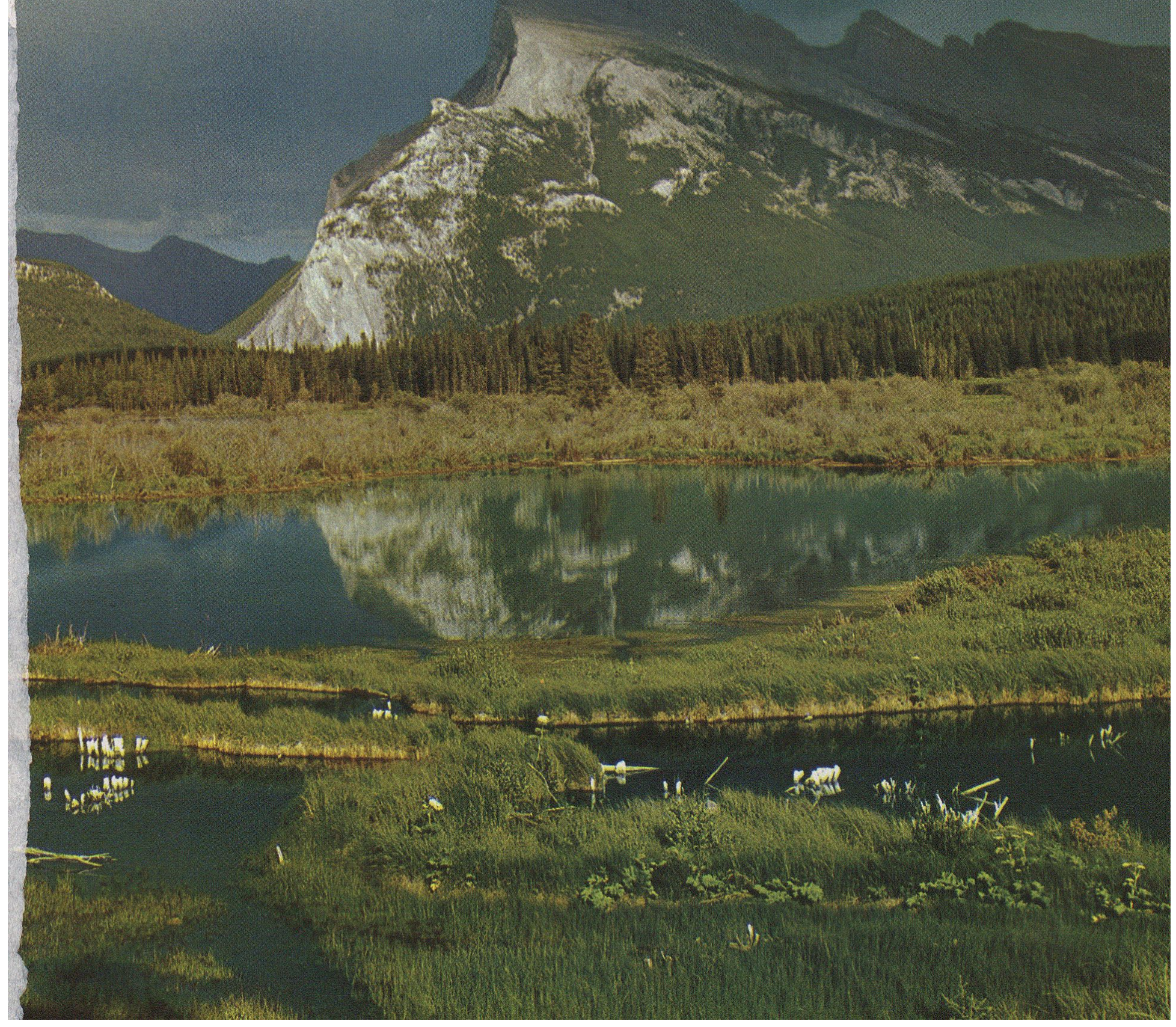




\section{Mount Rundle}

Wie das Matterhorn für Zermatt, so ist der Mount Rundle das Wahrzeichen von Banff, der Touristenstadt im südwestlichen Teil der Provinz Alberta in Kanada. Im Gegensatz zum Matterhorn kann aber der Mount Rundle von jedem willensstarken Touristen bestiegen werden. Ein $10 \mathrm{~km}$ langer «hiking trail» führt an der weniger steilen, bewaldeten Südwestflanke von Banff bis auf eine Höhe von $2300 \mathrm{~m}$, die restlichen 600 Höhenmeter werden über vegetationslose Kalkplatten zurückgelegt. Vom Gipfel eröffnet sich ein unvergleichlicher Ausblick auf die zahlreichen Bergspitzen der Rocky Mountains und in das vom Bow River entwässerte Tal, durch das der Trans-Canada-Highway und die historische Canadian-Pacific-Railway seit Pionierzeiten Menschen und Güter durchs Gebirge nach der Westküste führten.

\section{Banff}

Dank Schwefelquellen, reizvoller Hochgebirgslandschaft und zentraler Lage im Banff National Park wurde Banff mit seinen 4000 Einwohnern eines der berühmtesten Fremdenzentren des Landes, dem imposante Hotels, Motels und Campingplätze sowie Schwimmbäder, Sport- und Skianlagen ein mondänes Gepräge verleihen. Nicht nur als Touristenzentrum, sondern auch als wichtiger Konferenzort errang Banff einen weit über die Grenzen Kanadas reichenden Namen. Die «Banff School of Fine Art», eine im Jahre 1933 gegründete Kunstschule der Universität Alberta, bietet während der Sommermonate alljährlich 600 Studenten aus ganz Kanada und den USA Gelegenheit, Kurse in Theater, Ballett, Zeichnen und Musik zu belegen.

\section{Banff National Park}

Der Mount Rundle ist eine Hauptattraktion für Kanadas ältesten Nationalpark, welcher im Jahre 1855, nach der Entdeckung der beiden Schwefelquellen am Sulfur Mountain durch die Vermessungsleute der Transkanadischen Eisenbahn, mit vorerst nur $25 \mathrm{~km}^{2}$ zum Rocky Mountain National Park deklariert wurde. 1907 auf Banff National Park umbenannt, wurde er 1950 auf seine heutige Größe von $6640 \mathrm{~km}^{2}$ erweitert. Innerhalb der Parkgrenzen darf Land nur auf die Dauer von 99 Jahren gemietet werden; der Bau von Gebäuden und jegliche Veränderung des Geländes unterliegen sehr strengen raumplanerischen Bestimmungen. Der Park umfaßt einige der höchsten Berge Kanadas, zahlreiche Seen, wie den traumhaft schönen Moraine Lake, einen Teil des Columbia Icefield und mehrere eindrückliche Gebirgsgletscher. Durch ein Reservat werden zahlreiche ortstypische Tierarten wie Wapiti, Elch, Hirsch, Dickhornschaf, Schneeziege, Schwarzund Grislybär geschützt. Die heutigen Landschaftsformen wurden stark durch die letzte Eiszeit geprägt, während welcher das Gebiet unter einem mehrere hundert Meter mächtigen Eispanzer lag. Das Columbia Icefield sowie die durch Endmoränen gestauten Seen Lake Louise und Moraine Lake sind eindrückliche Überreste und Zeugen jener Zeit. Die Maximalstände der Gletscher während der historischen kleinen Eiszeit lassen sich, ähnlich wie in den Alpen, anhand gutausgebildeter End- und Seitenmoränen erkennen. Mehr als $1000 \mathrm{~km}$ Wanderwege nebst unzähligen, genau kartierten Bergtouren sowie guterschlossenen Winterskigebieten ziehen alljährlich über zwei Millionen Besucher in diesen beliebtesten Park Kanadas.

In Banff und in den weiter im Gebirge liegenden Fremdenzentren Golden, Jasper und Revelstock sind zahlreiche Schweizer ansäßig, die an der Erschließung dieser Bergregion beteiligt waren und heute als Bergführer und Skilehrer den Touristen zur Verfügung stehen.

\section{Geologie}

Der Mount Rundle besteht aus paläozoischen Sedimenten (Fig. 1). Am Ende des Mesozoikums hoben sich diese mehrere hundert Meter mächtigen Ablagerungen über das Meeresniveau, um gleich wieder teilweise abgetragen zu werden. Im Tertiär begann in den heutigen Rocky Mountains die Auffaltung, die zeitlich parallel zur Alpenbildung verlief. $\mathrm{Da} ß$ die Erdkruste noch heute nicht zur Ruhe gekommen ist, zeigen die vereinzelt vorkommenden Erdbeben, wie z. B. jenes, das 1959 das benachbarte Montana heimsuchte. Diese paläozoisch gebildeten und tertiär gefalteten

Konrad Steffen, Geographisches Institut, ETHZ,

Sonneggstraße 5, 8006 Zürich. 


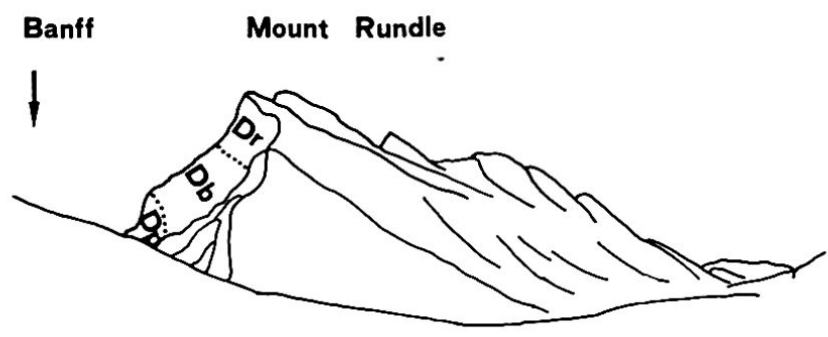

Fig. 1 Die paläozoischen Sedimentschichten des Mount Rundle

Dr: Rundle Formation, Db: Banff Formation, beide oberes Devon und Dp: Palliser Formation, mittleres Devon.

Sedimente bilden den Hauptteil der kanadischen Rocky Mountains östlich der Achse Bow River und North Saskatchewan River.

Der unterste Teil des Mount Rundle besteht aus den grauen Kalken und Dolomiten der $300 \mathrm{~m}$ mächtigen Palliser Formation; darüber liegen die braunen Kalke der Banff Formation.

Die oberste Folge (im Farbbild als leichtabfallende, z. T. bewaldete Flanke sichtbar) verlieh durch ihre eigenartig herauserodierte Form dem Mount Rundle seinen Namen. Sie besteht aus grauen Meeresmuschelkalken, die einem seichten, warmen Meer entstammen. Dieselben Schichten tauchen gegen Osten auf $1000 \mathrm{~m}$ Tiefe unter die Oberfläche der Prärien und beherbergen die dortigen großen Öl- und Gaslagerstätten.

\section{Die Verkehrserschließung}

Die historisch interessante Verkehrserschließung der Rocky Mountains begann Ende des letzten Jahrhunderts mit der Bildung der Föderation Kanada. British Columbia, durch die Rocky Mountains und die Prä- rien von den Bündnispartnern isoliert, lief Gefahr, an die USA abzufallen, worauf sich das kanadische Parlament verpflichtete, innerhalb von zehn Jahren die transkontinentale Eisenbahn zur Erschließung des -Westens zu bauen. British Columbia war im Aufschwung begriffen und dem jungen Staat der Erhaltung wert. Doch die Einlösung dieses Versprechens erwies sich als gordischer Knoten, da die riesigen Zwischengebiete der Prärien und der Rocky Mountains vorerst unüberwindbar schienen. Schon drohte British Columbia mit dem Austritt aus dem Bund, als sich das kanadische Parlament zur Lösung dieses Problems an die Privatwirtschaft wandte. Sechs verwegene, millionenschwere Unternehmer schufen ein Syndikat, das sie Canadian Pacific nannten - ein Hinweis auf das so schwer erreichbare Ziel. Die damals gegründete Gesellschaft nimmt noch heute eine Monopolstellung in der kanadischen Privatwirtschaft ein; sie besitzt neben großen Ländereien zahlreiche Luxushotels von Quebec bis Victoria, viele davon, wie z. B. Banff Springs und Lake Louise, sind im viktorianischen Stil gebaut. Später kamen auch Schiffahrtsrouten und Luftverkehrslinien dazu. Ihre Eisenbahn, deren Bau 1881 mit Hilfe von Tausenden von eigens hiefür eingeführten chinesischen Arbeitern in Angriff genommen wurde, konnte bereits 1886 dem Verkehr freigegeben werden. Heute bereichern "China Towns" viele Städte entlang dieser transkontinentalen Bahn. Dank der damaligen Linienführung, welche aus Konkurrenz zur amerikanischen Eisenbahn möglichst nahe der Grenze gebaut wurde, erschloß man eines der schönsten Gebiete Kanadas, den Banff National Park mit dem Mount Rundle.

Das Farbbild aus dem Bildband KANADA von Walter Weiss wurde uns freundlicherweise vom Verlag Kümmerly + Frey zur Verfügung gestellt. 